\title{
A MODEL FOR TESTING TECHNOSTRESS IN THE ONLINE EDUCATION ENVIRONMENT: AN EXPLORATORY STUDY
}

\author{
Queen Ester Booker, Minnesota State UniversityMankato,queen.booker@mnsu.edu \\ Carl M. Rebman, Jr, University of San Diego, carlr@sandiego.edu \\ Fred L. Kitchens, Ball State University,fkitchens@bsu.edu
}

\begin{abstract}
Higher education is adopting information technologies to provide students with opportunities for $24 / 7$ educational access. Part of this adoption is driven by perceived student demand to have anytime, anywhere access to educational content. Technology-related stress (technostress) is already common in today's electronic age. Working in the online educational environment adds additional levels to this type of stress. This paper presents an instrument to measure technology related stress for online students. Existing instruments used to measure general technology related stress as well technology related stress in the workplace were consulted for preliminary question development. The questions were tested using a convenience population of students and the results indicate there is a relationship between technostress and student outcomes in the online environment.
\end{abstract}

KEYWORDS: Information and communications technology (ICT), technostress, online education environment

\section{INTRODUCTION}

The introduction of technology based-learning management systems (LMS) has afforded educational institutions the ability to use online technologies to aid in the learning process. Faculty members are encouraged to think about how to use new learning technologies for online instruction and supplement the class with additional electronic content and in many cases, offer courses 100\% online. Harvard's massive online open courses, Carnegie Mellon's Open Learning Initiative, Education-Portal and the Monterey Institute for Technology and Education's National Repository of Online Courses, are examples of how some institutions are using technology to help educate But there are local initiatives as well, with faculty and publishers' developing online content to supplement what happens in the classroom, and as mentioned before, offering classes completely online. For courses that are $100 \%$ online students could spend as many as 6 hours per week per course, depending on the number of credits and the length of the course, utilizing various learning tools designed to facilitate engagement with the course content.

Prior studies suggest that the use of technology under certain circumstances can induce stress. Stress is defined by Webster's dictionary "A mentally or emotionally disruptive or upsetting condition occurring in response to adverse external influences and capable of affecting physical health, usually characterized by increased heart rate, a rise in blood pressure, muscular tension, irritability, and depression." According to Jay Winner, author of Take the Stress out of Your Life [26], stress increases the risk of conditions like obesity, heart disease, Alzheimer's disease, diabetes, depression, gastrointestinal problems, and asthma. So stress from any source for any sustained amount of time could have a detrimental effect on a person's life.

\section{Definition of Technostress}

These studies also suggest that working with technology can induce its own type of stress, referred to as technostress. Technostress was defined by Wang, et. al [23] is a "reflection of one's discomposure, fear, tenseness and anxiety when one is learning and using computer technology directly or indirectly that ultimately ends in psychological and emotional repulsion and prevents one from further learning or using computer technology.' Salanova, et. al, [20] also proposed a definition of the technostress experience at work as a "negative psychological state associated with the use or threat of ICT use in the future. They found that a technostress experience can be related to feelings of anxiety, mental fatigue, skepticism and inefficacy' (p. 1).

Walz [25] examined the relationship between technology and stress to find out what the stress related issues are, to what extent does "technostress" affect our personal lives and overall to gain a better understanding of the consequences of too much technology use. She found thirty-eight percent of the respondents almost always feel 
anxiety when they do not have their cell phone on their person, and $58 \%$ always check their cell phone the instant they get an alert for an incoming text or email. It was also found that "blurring boundaries" exist between the workhome environments. Overall, her results corroborate that the phenomenon known as "technostress" exists.

Brod [5], reported that employees at all levels of the organization experience some level of stress related to the use of information and computer technologies (ICT) at work. Other studies have showed that the type of techno-stress experienced vary and include data smog, multitasking madness, computer hassles, burnout, techno-addiction, and techno-strain (Salanova, et. al [20] and Brillhart [4]).

Much of the prior research in technostress has examined the work environment or the general environment. No current study has been found that examines and measures technostress in the educational environment. Reasons for this may be that online learning is still fairly young when compared to using technology at home or at work. Although online courses have been available since 1995, it is only within the past decade that online education has become mainstream, primarily because federal and state financial aid can now be applied to these programs. For example, in 2012, the percentage of institutions offering online courses and full programs were: 72.9 percent for private for-profit colleges, 48.4 percent of private non-profit, and 70.6 percent of public college [3]. Given that a full-time online student could spend as much as 40 hours per week using learning technologies, it is important that schools be able to measure technostress and if it is significant, examine how online courses can be designed to minimize the amount or level of technostress experienced by students.

\section{RESEARCH METHODOLOGY}

The purpose of this study is to develop an instrument to measure technostress for online students and identify factors that influence that stress. The study used several steps to develop the instrument, beginning with a pre-experimental design to capture direct attitudes while engaging in online content, followed by a comparison of survey items in existing literature, and ending with an exploratory study using the preliminary instrument to compare results of faceto-face only students with online only students to determine which items measure technostress factors that significantly differ for online students from face-to-face students.

\section{Pre-experimental design}

In pre-experimental design, there was no control group. A single group of participants were studied, and there is no comparison between a treatment group and a control group. For this study, students enrolled in an online Principles of Management course were offered bonus points towards their final grade for their participation in journaling their experiences while taking their online classes. 40 out of 60 students participated in the journaling and each provided at least ten pages of useful text for analysis. The journaling required students to document their feelings, both positive and negative, at regular intervals during the eight week course. 19 of the participants were men and 21 were women. The average age was 26 with a range from 21 to 35.10 of the students were international or had English as their second language; the rest were from the United States with English as their first language. For anonymity purposes the students were not identified by domestic US ethnicities.

The journals were manually analyzed for triggers, factors or indicators of stress related to the use of the learning management system or other learning tools, especially when the technology failed. Anger, frustration, insecurity, isolation, fear, disgust, anxiety, depressed, distressed, yelling, excessive working out, and impatience were commonly used terms to express negative feelings towards the technologies used in the learning management system and the comments were not limited to the Principles of Management course content or educational tools. Excite, ecstatic and happy were terms commonly used to express positive feelings but usually in relation to a grade or the completion of an assignment. Rarely were positive terms used in regards to the technology.

The pre-experimental design confirmed there was stress related to the use of the technology and not just the course content. We used the results of the pre-experimental design to develop a conceptual framework. The conceptual framework identifies research variables, and potential relationships among the variables, and "sets the stage" for representing the questions to use in the actual instrument. We used the most frequently used terms related to stress and that related to the use of the technology to narrow the questions in existing instruments used to measure technostress. 


\section{Instrument Development and Questionnaire Design}

After confirming stress existed from using the learning technologies, we examined the literature to identify relevant questions for the instrument, particularly Compeau and Higgins [10, 11], Hudiberg and Necessary [13], and Wang, et. al [23]. Content validation involved interviews with ten students enrolled in online courses. During these interviews, we asked them to comment on the relevance and clarity of the questions within the context of technostress situations and associated organizational response mechanisms as they experienced them. Based on their feedback, we developed the final measurement items for large scale data collection. This strategy follows similar methods adopted in comparable papers in recent literature (Salisbury [21], Chin, et. al [9], Ragu-Nathan [19], given the lack of prior theoretical research on technostress. All items were measured on a five-point Likert scale: from 1 ("strongly disagree") to 5 ("strongly agree"). A sixth option of "Not Applicable" or "I do not know" was also provided.

\section{Data Collection}

Data was collected from online-only students who were a convenience sample from one regional midwestern university. Students were compensated with bonus points for completing the questionnaire. Emails were sent to students describing the nature and purpose of the study and asking them if they would be interested in participating. They were requested to ask for the questionnaire link if they were interested and to return the completed questionnaire using a link provided by the researchers. Students were informed that participation was voluntary and that their responses would be confidential to the researchers with only a list of participants sent to the instructor to award the bonus points. A total of 101 questionnaires were completed. Sample characteristics are given in Table 1.

Table 1. Sample Characteristics

\begin{tabular}{|l|l|l|l|}
\hline Gender & Frequency & Educational Level & Frequency \\
\hline Male & 47 & Junior & 63 \\
\hline Female & 49 & Senior & 29 \\
\hline Missing & 5 & Missing & 9 \\
\hline Total & $\mathbf{1 0 1}$ & Total & $\mathbf{1 0 1}$ \\
\hline Age & Frequency & Computer Confidence & Frequency \\
\hline Below 22 & 58 & Not at all & 1 \\
\hline 22 to 31 & 29 & Somewhat not confident & 3 \\
\hline 32 to 41 & 7 & Neutral & 7 \\
\hline over 41 & 2 & Somewhat confident & 29 \\
\hline Missing & 5 & Completely confident & 61 \\
\hline Total & $\mathbf{1 0 1}$ & Total & $\mathbf{1 0 1}$ \\
\hline
\end{tabular}

\section{Development and Validation of Technostress Creators and Technostress Inhibitors Constructs for the Online Environment}

We conducted an exploratory factor analysis by splitting the results into two random samples. Set 1 was comprised of 51 cases that were used to develop the construct. The second set was used to validate the results from the first set. We had 30 items for technostress creators and 15 items for technostress inhibitors in the questionnaire. The exploratory factor analysis of Set 1 yielded a five-factor structure for technostress creators consisting of 20 of the 30 items and a three-factor structure for technostress inhibitors consisting of only 11 if the 15 items. The results are available upon request from the authors.

We followed the exploratory factor analysis with a confirmatory factor analysis (CFA) using Set 1 . We validated the CFA using the second set of data. Items having high correlation among their error terms were deleted. The final factor structures are shown in Table 2. 
Table 2 CFA Final Factor Structures

Techno-overload (reliability $=0.83$, mean $=3.36$, standard deviation $=0.71$ )

TSC_3-I am forced by this technology to work with very tight time schedules.

TSC_4-I am forced to change my study habits to adapt to new technologies.

TSC_5-I have a higher workload because of increased technology complexity.

TCS_6-I have a higher workload because of the online learning environment.

TSC_7- I have to spend a lot of time everyday reading an overwhelming amount of e-mail messages.

TSC_8-I have to spend a lot of time everyday reading an overwhelming amount of discussion board messages.

Techno-invasion (reliability $=0.73$, mean $=3.42$, standard deviation $=0.68$ )

TSC 10 - I have to sacrifice my vacation and weekend time to keep current on changes to the courses and learning environment.

TSC_11-I feel my personal life is being invaded by this learning environment.

TSC_13-I spend less time with my family due to this technology.*

Techno-complexity (reliability $=0.77$, mean $=2.06$, standard deviation $=0.75$ )

TSC_14-I do not find enough time to study and upgrade my technology skills to meet the needs of the program.

TSC_15-I find new students to this program know more about computer technology than I do.

TSC_16-I often find the learning tools too complex for me to understand and use effectively.

TSC_17-I do not know enough about this technology to complete my courses satisfactorily.

Techno-insecurity (reliability $=0.81$, mean $=3.01$, standard deviation $=0.74$ )

TSC_20-I do not share my knowledge with my peers for fear of being accused of cheating.

TSC_21-I find younger students in this program know more about computer technology than I do.

TSC_23-I find younger students more easily adapt to changes in the learning environment.

TSC_24-I feel constant threat to my ability to complete the program due to new technologies.

Techno-uncertainty (reliability $=0.77$, mean $=3.02$, standard deviation $=0.68$ )

TSC_26-I have to work harder because of delays from hardware, software and network problems.

TSC_27-There are always new developments in the technologies we use in our program.

TSC_28-There are constant changes in computer software in our program. 


\begin{tabular}{|c|c|}
\hline Technostress inhibitors & \\
\hline \multicolumn{2}{|l|}{ Literacy facilitation (reliability $=0.68$, mean $=3.16$, standard deviation $=0.57$ ) } \\
\hline $\begin{array}{l}\text { TSI_1_Our program encourages knowledge sharing to help deal with new } \\
\text { technology.* }\end{array}$ & .547 \\
\hline $\begin{array}{l}\text { TSI_3-Our program provides end-user training before the introduction of new } \\
\text { technology. }\end{array}$ & .526 \\
\hline $\begin{array}{l}\text { TSI_4_OOur program fosters a good relationship between IT department and } \\
\text { students. }\end{array}$ & .687 \\
\hline $\begin{array}{l}\text { TSI_5-Our program provides clear documentation to students on using new } \\
\text { technologies. }\end{array}$ & .531 \\
\hline TSI_6-Our program provides training to new students. & .522 \\
\hline \multicolumn{2}{|l|}{ Technical support provision (reliability $=0.71$, mean $=3.22$, standard deviation $=0.68$ ) } \\
\hline TSI_7-Our end-user help desk is well staffed by knowledgeable individuals. & .574 \\
\hline TSI_9—_Our end-user help desk is responsive to end-user requests. & .592 \\
\hline $\begin{array}{l}\text { TSI_10_-Our end-user help desk does a good job of answering questions about } \\
\text { technology.* }\end{array}$ & .622 \\
\hline \multicolumn{2}{|l|}{ Involvement facilitation (reliability $=0.78$, mean $=2.82$, standard deviation $=0.71$ ) } \\
\hline TSI_12-Our students are consulted before introduction of new technology. & .547 \\
\hline TSI_13-Our students are involved in technology change and/or implementation. & .629 \\
\hline TSI_14_-Our students are encouraged to try out new technologies. & .521 \\
\hline
\end{tabular}

Based on item contents, the five factors for techno- stress creators were named techno-overload, techno-invasion, techno-complexity, techno-insecurity, and techno-uncertainty. These factors can be regarded as different aspects or dimensions of technostress as described by Ragu-Nathan [19] and repeated below.

Techno-overload describes situations where ICTs force users to work faster and longer. Techno-invasion describes the invasive effect of ICTs in situations where employees can be reached anytime and feel the need to be constantly connected, thus blurring non-personal and personal contexts. Techno-complexity describes situations where the complexity associated with ICTs leads users to feel inadequate with regard to their computer skills and forces them to spend time and effort in learning and understanding ICTs. Techno-insecurity is associated with situations where users feel threatened about technology because of automation from ICTs or to other people who have a better understanding of ICTs. Techno-uncertainty refers to contexts where continuing ICT changes and upgrades unsettle users and create uncertainty so that they must constantly learn and educate themselves about new ICTs.

The three factors for technostress inhibitors were named literacy facilitation, technical support provision, and involvement facilitation. These represent mechanisms that decrease the effect of technology-related stress. Literacy facilitation describes mechanisms that encourage and foster the sharing of ICT-related knowledge. Literacy facilitation reduces technostress because it helps users understand ICTs and their uses, and enables them to cope with the demands of learning new ICTs. Technical support provision describes activities related to end-user support that reduce the effects of technostress by solving users' ICT problems relating. Involvement facilitation helps alleviate technostress by keeping users informed about the rationale for introducing new ICTs, by letting them know about the effects of such introduction, and by encouraging them to use and experiment with new ICTs. 


\section{Conceptual Model Testing on the Full Sample}

The reliability of the constructs was calculated on the combined sample (Set 1 and Set 2). Means, standard deviation, and reliability are shown in Table 2 for the technostress inhibitors and technostress creators. The means and standard deviation for the remaining variables are shown in Table 3.

Table 3. Means and standard deviation for program variables

\begin{tabular}{|c|}
\hline Program satisfaction \\
\hline $\begin{array}{l}\text { PS } 1-\text { I like doing the things I do in the program. ( mean=4.22, standard } \\
\text { deviation=0.68) }\end{array}$ \\
\hline $\begin{array}{l}\text { PS 2-I feel a sense of pride in participating in the program. ( mean }=3.68 \text {, standard } \\
\text { deviation }=0.53 \text { ) }\end{array}$ \\
\hline PS_3-My program is enjoyable. ( mean $=4.00$, standard deviation $=0.63$ ) \\
\hline Program commitment \\
\hline $\begin{array}{l}\text { PC 1-I would be happy to graduate from this program. ( mean=4.39, standard } \\
\text { deviation=0.58) }\end{array}$ \\
\hline $\begin{array}{l}\text { PC 2-I enjoy discussing my program with people outside it. ( mean }=3.22 \text {, standard } \\
\text { deviation }=0.78 \text { ) }\end{array}$ \\
\hline $\begin{array}{l}\text { PC 3-I really feel as if this program's problems are my own. ( mean }=2.43 \text {, standard } \\
\text { deviation }=0.73 \text { ) }\end{array}$ \\
\hline $\begin{array}{l}\text { PC 4 - This program has great deal of personal meaning for me. ( mean }=4.62 \text {, } \\
\text { standard deviation }=0.53 \text { ) }\end{array}$ \\
\hline Continuance commitment \\
\hline $\begin{array}{l}\text { CI_1-Too much of my life would be disrupted if I decided I want to leave my } \\
\text { program right now. ( mean }=3.42 \text {, standard deviation }=0.71)\end{array}$ \\
\hline $\begin{array}{l}\text { CI_2 - Right now staying with my program is a matter of necessity as much as } \\
\text { desire. ( mean }=2.78 \text {, standard deviation }=0.76 \text { ) }\end{array}$ \\
\hline $\begin{array}{l}\text { CI_3-I believe that I have too few options to consider leaving this program. } \\
(\text { mean }=2.42 \text {, standard deviation }=0.68)\end{array}$ \\
\hline $\begin{array}{l}\text { CI_4-It would be very hard for me to leave my program right now even if I } \\
\text { wanted to. ( } \text { mean }=2.67 \text {, standard deviation }=0.53)\end{array}$ \\
\hline
\end{tabular}

The Cronbach's alpha values range for the data were between 0.71 and 0.79 which is greater than the recommended minimum value of $0.7[18,12]$. We evaluated the model fit on the basis of chi square/df. The chi square index is sensitive to sample size and sample departures from multivariate normality. Chi square/df adjusts for the degrees of freedom. Appropriate values for chi square/df should exceed 1 and be less than $5[21,9]$. These results are shown in Table 4.

Table 4. Test for Discriminant Validity

\begin{tabular}{|l|l|l|l|l|}
\hline & Model & $\begin{array}{l}\text { chi- } \\
\text { square }\end{array}$ & df & $\begin{array}{l}\text { chi - } \\
\text { squared/df }\end{array}$ \\
\hline 1 & First order correlated model & 983 & 355 & 2.77 \\
\hline 2 & Technostress creator second order model & 318 & 141 & 2.26 \\
\hline 3 & Technostress inhibitors second order model & 78 & 24 & 3.25 \\
\hline
\end{tabular}

A first order correlated measurement model was used to check for the discriminant and convergent validities of the constructs. The results showed were no significant error correlations among any of the items, thus indicating good discriminant and convergent validities.

To verify that the five-factor structure indicated a second order technostress creators construct and the three-factor structure a second order technostress inhibitor construct, a first order correlated model was compared with a second 
order model for each construct. The fit indices, shown as "Model 2" and "Model 3" in Table 3, exceed recommended values. The target coefficient $[7,8]$, i.e., the ratio of the chi square value for the first order model to that for the second order model, exceeded the recommended value of $80 \%$. For technostress creators (Model 2), the chi square value for the first order model was 356 and for the second order model was 318, giving a target coefficient of $89.3 \%$. For technostress inhibitors (Model 3), the chi square value for the first order model was 93 and for the second order model was 78 , giving a target coefficient of $84 \%$. Hence the values of the gamma coefficient, fit indices, and the target coefficient show evidence of second order constructs.

We then tested we tested the relationships among technostress creators, technostress inhibitors, course satisfaction, and organizational commitment using a structural equation modeling analysis (SEM). The results of the SEM analysis show that the fit indices are satisfactory (see Table 5) and the path coefficients are significant. We interpret the results to prove that technostress creators decrease course satisfaction and technostress inhibitors increase course satisfaction and continuance commitment. To test for possible moderating effects of technostress inhibitors on the relationship between technostress creators and job satisfaction, we followed the methodology discussed by Sharma [22], McKeen [16], and Ragu-Nathan [19].

Table 5. Result of SEM analysis

\begin{tabular}{|l|c|c|c|c|c|c|}
\hline & $\begin{array}{c}\text { chi } \\
\text { squared }\end{array}$ & df & $\begin{array}{c}\text { chi- } \\
\text { square/df }\end{array}$ & $\begin{array}{c}\text { chi squared } \\
\text { baseline }\end{array}$ & $\begin{array}{c}\text { df } \\
\text { baseline }\end{array}$ & $\begin{array}{c}\text { chi-square/df } \\
\text { baseline }\end{array}$ \\
\hline Model 4 & 134 & 35 & 3.828571 & 1012 & 369 & 2.742547 \\
\hline
\end{tabular}

We first regressed course satisfaction against technostress creators, technostress inhibitors and their product, with the regression coefficient of the product signifying the effect of the moderating relationship. We repeated this for each of the first order factors of technostress creators and technostress inhibitors. The results do not support a moderating effect. In this context, Wall [24], Landsbergis [14] and Ragu-Nathan [19] note that most studies from the stress literature in which moderator relations have found support use objective rather than perceptive measures for the stressors.

We also tested for the effects of the three individual characteristics (gender, age, and computer confidence) on technostress by regressing these variables on technostress creators. Gender was recorded as "male" or "female." Age was measured on a 1 to 4 ordinal scale according to the scales shown in Table 1. Computer confidence was measured on a 1 to 5 scale varying from "not at all confident" to "completely confident." The regression coefficients were significant for all the variables. Our results showed that females and older people experienced more technostress than males and that technostress decreased as computer confidence increased. The finding with respect to gender is consistent with what we expected. Past research indicates that females experience more technostress than men in general [1]. The results for age were also expected as research regarding technostress and age suggest that younger people experience less technostress than older people [17].

\section{RESULTS AND DISCUSSION}

The research-related contribution of this paper from an information systems perspective is the conceptual shape and empirical validation of technostress in the online learning environment for students. The results affirm that technostress can be analyzed in terms of, and considered a conceptual enhancement to, existing theoretical frameworks for studying stress in the online educational environment.

Instructors and instructional designers can use the items described in the resulting models to ascertain the presence or absence of factors that create technostress and seek to minimize the disruptors to the learning environment. They may also recognize that the organizational mechanisms described in technostress inhibitors can be effectively used to increase course as well as program satisfaction and commitment to continue (e.g., retention), and thus mitigate the negative outcomes of technostress. The findings with respect to relationships between the variables related to individual differences and technostress creators have implications for managing the effects of age, gender, and computer confidence on technostress. 


\section{LIMITATIONS}

Though this study was exploratory, the empirical results may be generalized to frame theoretical relationships about technostress $[15,17]$ especially since the results are consistent with what has been reported in the literature regarding gender, age and confidence in the work and general environments.

First, we only used one validation model (chi-squared/df). Additional validations such as Goodness-of-Fit, Adjusted Goodness-of-Fit, Normed Fit and Comparative Fit should be used as they assess model fit by comparing the theoretical model to a baseline model. Goodness of Fit (GFI) indicates the relative amount of variance and covariance explained by the model. Adjusted Goodness-of-Fit index (AGFI) adjusts GFI for the degrees of freedom. Normed Fit Index (NFI) and Comparative Fit Index (CFI) assess model fit by comparing the theoretical model to a baseline model.

Also, our sample was small and a convenience sample from one institution. Larger and more diverse data sets are necessary for better validation. Also, longitudinal studies must be used to measure technostress before and after the implementation of specific inhibitor mechanisms. Exploring relationships between technostress and learning would lead to further refinement of the model. The possibility of individual differences and technostress inhibitors moderating the relationships in the model should also be investigated. Another future research possibility is that of using formative modeling to identify technostress creators and technostress inhibitors and to examine whether the primary relationships in the model differ for respondents from various demographic groups as well as the learning environment or the actual technology tools/number of technology tools used.

\section{CONCLUSIONS}

Information technology has had a significant impact on access to education, providing a 24/7 anytime anywhere model. This access has had a significant influence on the processes and outcomes of how we learn. Organizations have wholeheartedly embraced the benefits of information technology as learning tools benefit from this flexibility which has also resulted in efficiencies in the learning process. However, the use of technology often "encourage" students to try and accomplish more tasks in less time, resulting in the creation of self-induced stressors that may impact their relationships with others as well as developing health conditions that may be irreversible. We expect ICTs change our jobs and eventually our behaviors in ways that we do not completely understand and the literature on stress literature is being increasingly recognized as a potential basis for understanding attitudes toward ICTs [1, 17, 23]. Technostress is an important fallout of the inevitable use of ICTs in organizations and is likely similar in the online education environment. Research illustrates the bivalent nature of their organizational influence. This research represents an attempt to develop a conceptual and empirical understanding of technostress and its outcomes in the online learning environment. We believe that the definitions and relationships developed in this paper can be used as bases for future studies in this area.

\section{REFERENCES}

1. Ahuja, M. K., J. B. Thatcher. (2005). Moving beyond intentions and towards the theory of trying. MIS Quart. 29(3, September) 427-459.

2. Allen, I.E. \& Seaman, J. (2013). Changing Course: Ten Years of Tracking Online Education in the U.S.. Babson Survey Research Group.

3. Allen, N. J., J. P. Meyer. (1990). The measurement and antecedents of affective, continuance, and normative commitment. J. Occupational Psych. 63 1-18.

4. Brillhart, P. E. (2004). Technostress in the workplace: Managing stress in the electronic workplace. $J$. Amer. Acad. Bus. 5(1/2) 302-307.

5. Brod, C. (1984). Technostress: The Human Cost of the Computer Revolution. Addison-Wesley, Reading, MA.

6. Burke, R. (1993). Organizational-level interventions to reduce occupational stressors. Work and Stress 7 77-87.

7. Carayon, P. (1993). Effect of electronic performance monitoring on job design and worker stress: Review of the literature and conceptual model. Human Factors 35(3) 385-395. 
8. Carayon, P. (1994). A longitudinal model test of Karasek's Job Strain model among office workers. Work Stress 7(4) 299-314.

9. Chin, W. W., A. Gopal, W. D. Salisbury. (1997). Advancing the theory of adaptation structuration: The development of a scale to measure faithfulness of appropriation. Inform. Systems Res. 8(4) 342-367.

10. Compeau, D. R., C. A. Higgins. (1995). Computer self-efficacy: Development of a measure and initial test. MIS Quart. 19 189-211.

11. Compeau, D., C. A. Higgins, S. Huff. (1999). Social cognitive theoryand individual reactions to computing technology: A longitudinal study. MIS Quart. 23 145-158.

12. Hair, J. F., R. E. Anderson, R. L. Tatham, W. Black. (1998). Multivariate Data Analysis with Readings, 5th ed. Prentice Hall, Upper Saddle River, NJ.

13. Hudiberg, R. A., J. R. Necessary. (1996). Coping with computer stress. J. Educational Comput. Res. 15(2) $113-124$.

14. Landsbergis, P. A., P. L. Schnall, J. E. Schwartz, K. Warren, T. G. Pickering. (1995). Job strain, hypertension, and cardiovascular disease: Empirical evidence, methodological issues, and recommendations for future research. S. L. Sauter, L. R. Murphy, eds. Organizational Risk Factors for Job Stress. American Psychological Association, Washington, D.C., 97-112.

15. Lee, A. S., R. L. Baskerville. (2003). Generalizing generalizability in information systems research. Inform. Systems Res. 14(3) 221-243.

16. McKeen, J. D., T. Guimaraes, J. C. Wetherbe. (1994). The relationship between user participation and user satisfaction: An investigation of four contingency factors. MIS Quart. 18(4) 427-451.

17. Morris, M. G., V. Venkatesh, P. L. Ackerman. (2005). Gender and age differences in employee decisions about new technology: An extension to the theory of planned behavior. IEEE Trans. Engrg. Management 52(1, February) 69-95.

18. Nunnally, J. C. (1978). Psychometric Theory. McGraw-Hill, New York.

19. Ragu-Nathan, T. S., Tarafdar, M., Ragu-Nathan, B. S., \& Qiang, T. (2008). The Consequences of Technostress for End Users in Organizations: Conceptual Development and Empirical Validation. Information Systems Research, 19(4), 417-433.

20. Salanova, M., Llorens, S., Cifre, E., and Nogareda, C. (2007) Technostress: Concept, measurement, and Prevention. Notatechia de Prevencion. 730. Madrid, Spain. INSHT

21. Salisbury, W. D., W. W. Chin, A. Gopal, P. R. Newsted. (2002). Research report: Better theory through measurement- Developing a scale to capture consensus on appropriation. Inform. Systems Res. 13(1) 91103.

22. Sharma, S., R. M. Durand, O. Gur-Arie. (1981). Identification and analysis of moderator variables. $J$. Marketing Res. 18(3) 291-300.

23. Wang, K., Shu, Q., and Tu., K. (2008). "Technostress under different organizational environments: An empirical investigation" Computers in Human Behavior, Vol. 24 Issue 6 Pg 3002-3013.

24. Wall, T. D., R. R. Jackson, S. Mullarkey, S. K. Parker. (1996). The demands-control model of job strain: A more specific test. J. Occupational Organ. Psych. 69(2) 153-166.

25. Walz, K. (2012). "Stress Related Issues Due to Too Much Technology: Effects on Working Professionals" (2012).MBA Student Scholarship. Paper 12. http://scholarsarchive.jwu.edu/mba student/12 accessed May 9,2014

26. Winner, J. Take the Stress out of your Life. (2003). DaCapo Press, Perseus Book Group, Philadelphia, PA. 